\title{
Influences on intentions to use a personal carbon trading system (NICHE - The Norfolk Island Carbon Health Evaluation Project)
}

\author{
Alex Hendry \\ Southern Cross Business School, Southern Cross University \\ Hogbin Drive \\ Bilinga, Qld, 4225, Australia \\ Email: alex.hendry@scu.edu.au \\ Gary Webb \\ School of Health and Human Sciences, Southern Cross University \\ Hogbin Drive \\ Coffs Harbour, NSW, 2450, Australia \\ Email: g.webb.23@student.scu.edu.au \\ Alicia Wilson \\ School of Health and Human Sciences, Southern Cross University \\ Hogbin Drive \\ Coffs Harbour, NSW, 2450, Australia \\ Email: a.wilson.32@scu.edu.au \\ Bruce Armstrong \\ Southern Cross Business School, Southern Cross University \\ Hogbin Drive \\ Coffs Harbour, NSW, 2450, Australia \\ Email: bruce.armstrong@scu.edu.au \\ Bill Smart \\ School of Business and Tourism, Southern Cross University \\ Bilinga, QLD, 4225, Australia \\ Email: bill.smart@scu.edu.au \\ Garry Egger \\ School of Health and Human Sciences, Southern Cross University \\ Lismore, NSW, 2482, Australia \\ Email:eggergj@gmail.com
}

\begin{abstract}
This paper presents the results of a baseline survey undertaken for the Norfolk Island Carbon Health Evaluation (NICHE) project and analyzes the relationships among key variables hypothesized as affecting respondents' intentions to use a personal carbon trading (PCT) system. The survey was delivered to all households on Norfolk Island and gathered information on respondent's attitudes towards climate change, PCT and health, as well as demographic and household information. The intention of the study was to investigate the relationship between health and climate change and whether attitudes can be influenced by an understanding of one's carbon footprint prior to the roll out of a PCT trial.
\end{abstract}

Keyword: Personal Carbon Trading, Personal Carbon Trading Systems, Global Warming, Environmental Behaviours 


\section{Introduction}

Obesity and greenhouse gas (GHG) emissions with the potential for inducing climate change are two modern and not unrelated world dilemmas ${ }^{1,2}$ Obesity significantly increases the risk of chronic disease and impacts quality of life $^{3}$ and GHG emissions not only have the potential to impact the environment but also present one of the largest public health threats of the 21 st centenary ${ }^{4}$. A common causality for both has been previously proposed in human behaviours e.g. personal inactivity through the use of carbon emitting fossilfuel powered transport, consumption of energydense, carbon intensive processed foods etc ${ }^{5,6}$ although this common link has not been widely canvassed in the literature. Given the relationship of causality it is reasonable to propose that a single intervention targeting behaviour change that reduces GHG emissions may prove beneficial to addressing both GHG emissions and obesity by encouraging more active transport and consumption of a healthier diet with less processed food.

Corporate Carbon Trading which is the currently favoured macro-economic option for reducing GHG emissions could have this effect if it sufficiently alters the economic levers to change corporate and individual behaviours. However corporate emissions make up only around 50-60\% of total GHG emissions. An additional proposal to change individual behaviour even further is Personal Carbon Trading (PCT) because it changes the dynamics of the micro-economics at a closer and more relevant level for the individual ${ }^{7}$.

Personal Carbon Allowances (PCAs) were first proposed by David Flemming ${ }^{8}$ in the UK as an equitable means of reducing the $40-60 \%$ of carbon emissions that come from downstream sources i.e. households and individuals in a population.

PCT is a sub-category of PCA developed at Oxford University ${ }^{9}$ and has been endorsed in part by the British Parliament with the recommendation that it be re-assessed at a later date, largely because of a lack of current confidence in its political acceptability ${ }^{10}$.

PCT works by allocating to every individual an equal number of tradable energy units (personal carbon allowance - PCA) per year, based on about $40 \%$ of a total budget (that includes both personal and corporate quotas) set by a central budgetary council. Each unit is equivalent to $1 \mathrm{~kg}$ of carbon released through energy usage. Trade of units is conducted either through existing credit cards or through a carbon card system administered by banks. Individuals who are left with carbon credits (i.e., those who are frugal with non-renewable energy use) are then able to sell these back into the marketplace thereby gaining financial benefit. Those who overuse their quota pay a premium price for extra energy use. (A complete summary of the proposed practical applications of the scheme is available elsewhere ${ }^{7}$ ).

Fossil fuel powered transport is a major contributor towards carbon emissions and climate change $^{11}$. Reliance on Fossil fuel powered transport for individuals and its associated decrease in active forms of transport are also seen as a major contributor towards the obesity epidemic ${ }^{12,13,14,15}$.

Meat is the largest contributor towards climate change of any food source ${ }^{16,17,18,19}$. Processed food and drink that contain sugars requires the second highest energy use of any food product behind meat ${ }^{19}$. An excess of animal based food products and highly processed energy dense food has been shown to increase the likelihood of obesity $^{20,21,22,23,24}$.

The rise in the prevalence of obesity has been linked to the increase in diabetes ${ }^{25}$. Other long term effects of obesity include increased risk of many cancers including cancer of the breast, endometrium, esophagus, kidney, pancreas, gall bladder, thyroid, ovary, cervix, and prostate, as well as multiple myeloma and Hodgkin's lymphoma ${ }^{26}$.

In theory at least, the process of PCT might encourage less use of fossil fuel powered transport and more involvement in active forms of transport e.g. walking/cycling because of the increased 'real' cost of fossil fuel energy. PCT might also encourage lower consumption of meat and highly processed food and drink products that are associated with a higher prevalence of obesity, chronic disease and environmental impact due to the additional greenhouse gas emissions associated with these products.

A problem with the current status of PCT is the difficulty of testing this in a whole country before its introduction because of a lack of knowledge about its political acceptability and a lack of practical operational detail for such a system. The proposed idea however lends itself to testing within a 'closed' system, such as an island, where both environmental and health metrics can be accurately 
measured. A difficulty with this is finding an island with an advanced enough economy, remote enough to be relatively closed and small enough to be manageable within a limited research budget.

Norfolk Island off the east coast of Australia is such a location. The population of Norfolk Island is reasonably representative of other developed locations. It also meets all of the criteria listed above, making it ideal to test the concept and political acceptability of Personal Carbon Trading in a closed island community. This is discussed in greater detail in the next section. Following sections cover the development of the conceptual model, the survey and the results of the statistical analysis.

\section{Research Background}

The Norfolk Island Carbon Health Evaluation (NICHE) was established in 2011 with the following research objectives:

- To assess whether personal carbon allowances are effective in reducing an individual's carbon footprint and what impact this has on health behaviours associated with obesity.

- To assess the political acceptability of introducing personal carbon trading (PCT) system into a population as a tool for reducing carbon emissions.

- To explore the relationship between positive health behaviours and pro-environmental behaviours.

Norfolk Island is a self-governing Australian protectorate. The size of the total resident population identified in the 2011 census was 1795 , with 1368 residents being identified as over 19 years of age. It is a relatively small volcanic island $(5 \times 8 \mathrm{~km})$, situated $1500 \mathrm{~km}$ from the east coast of Australia and approximately $1200 \mathrm{~km}$ from the northern tip of New Zealand. The local economy is largely driven by tourism, which peaked at 42000 visitors in 2001 and since declined to average of 24000 visitors annually over the past 4 years which has seen a significant downturn in the local economy.

The price of most commodities, especially electricity and fuel, are significantly higher than on the Australian mainland. Given the small nature of the island, locals are only required to drive small distances, some of which could easily be walked. Importation of common household items is expensive and with limited waste disposal facilities many items are reused numerous times before being thrown away. General observation suggest that the population is already very resource conscious and therefore further reductions in $\mathrm{GHG}$ emissions are likely to come through advances in technology or behaviours relating to consumption (including food) and means of transport. An intervention designed to further reduce GHG emissions might therefore encourage active transport behaviours.

This makes Norfolk Island a suitable environment to test the proposed research questions as inputs and outputs to the Island are more easily able to be measured than in other populations (e.g. Australia) and the project can be run as a community based initiative. Additionally, given that the population is already electricity conscious and reuses a lot of household items, it will help to identify what other behaviours may be influenced by a GHG emission reduction intervention which otherwise might not be recognised in other populations.

This paper aims to explore how an individual's attitudes and behaviours associated with their health, well-being, the environment, carbon emissions and climate change affects their intentions to use a personal carbon trading (PCT) system.

\section{Conceptual Model}

To understand what factors might possibly affect PCTS usage intentions and develop a conceptual model, examination of literature relevant to the research being undertaken focused on the following areas:

- Information systems success

- PCT

- Health and obesity

- Carbon emissions and climate change

- Links between obesity and an individual's carbon footprint

The literature on information systems success, PCT and the links between obesity and an individual's carbon footprint was of most relevance and underpinned the development of the conceptual model.

The following four PCTS models identified from the literature were also examined. These models 
were detailed in the literature which meant specific characteristics could be determined to be taken forwards in the system being rolled-out on the Island for the NICHE project.

- Cap and Share (C\&S) - Proposed by the Foundation for the Economics of Sustainability (FEASTA) in 2008

- $\quad$ Tradable Energy Quotas (TEQ) Originally known as Domestic Tradable Quotas (DTQ) TEQ's were first proposed by David Fleming in June 1996

- Personal carbon allowances (PCA) Proposed by Mayer Hillman and Tina Fawcett in 2004

- Household Carbon Trading - Proposed by Debbie Niemeier and others in 2008

Following an examination of the relevant literature it was hypothesized that an individual's PCTS usage intentions are influenced by:

- $\quad$ Self-health evaluation - Information on an individual's self-evaluation of their own health and weight

- $\quad$ Attitudes and behaviours towards health Individuals who have positive attitudes and behaviours about health and weight management and who exercise regularly are more likely to have a positive PCT usage intentions

- $\quad$ Attitudes and behaviours towards the environment - Individuals who have positive attitudes and behaviours towards the environment are more likely to have a positive PCTS usage intentions

- $\quad$ Attitudes and behaviours towards carbon emissions and climate change - Individuals who have positive attitudes and behaviours towards their carbon footprint, reduction of their carbon emissions and are concerned about climate change are more likely to have positive PCTS usage intentions.

This is illustrated on the Conceptual Model in Appendix 1.

\section{The NICHE Survey}

Data was collected via a questionnaire that was hand delivered to every house on Norfolk Island. It was in part based on survey items from existing surveys and publications including:
- $\quad$ Baseline Survey of Australian attitudes to climate change ${ }^{27}$

- Australians' views of climate change ${ }^{28}$

- Who cares about the environment in $2009 ?^{29}$

- $\quad$ The WHO STEP wise approach to chronic disease risk factor surveillance $e^{30}$

- Development of the World Health Organization Global Physical Activity Questionnaire (GPAQ) ${ }^{31}$

- Personal carbon allowances: a pilot simulation and questionnaire ${ }^{32}$

- $\quad$ Norfolk Island 2011 Census of Population and Housing ${ }^{33}$

Additional questions were developed by the NICHE research team to cover aspects of the research for which there were no existing studies

To assess PCT usage intentions a section of the survey included questions specifically related to users' acceptance of and satisfaction with a PCT. The questions and scales in this section of the survey were influenced in part by the questions used to test the user satisfaction and technology acceptance information system success models.

The survey had a number of sections and it was the following questions that were the items used in the analysis reported in this paper.

- Questions B1 - B13 - included as measures of the attitudes and behaviors towards health, attitudes and behaviors towards the environment and attitudes and behaviors towards carbon emissions and climate change components of the conceptual model.

- Questions B14 - B19 - included as measures of the attitudes and behaviors towards the environment component of the conceptual model.

- Questions A9, A10, A12 and C1 - included as measures of the self health evaluation component of the conceptual model.

- Questions E1 - E10 - included to measure users' usage intentions towards a PCTS. The ten questions in this section were adapted from scales used by researchers examining user information system satisfaction and technology acceptance. The questions in this section are intended to measure the information needed for the dependent variable PCTS usage intentions of the 'information systems' component of the study. 
The survey was open to any permanent resident of Norfolk Island or any long term nonresident over the age of 18. Five NGO's were employed to hand deliver a survey to every household on the Island. Completed surveys could be returned by mail, dropped off at the local post office or supermarket or picked up by NICHE staff.

In total over 400 responses were received which represents over $60 \%$ of occupied households on Norfolk Island and almost $30 \%$ of the population over 18 years of age.

\section{Testing the Conceptual Model}

The conceptual model in Appendix 1 shows four independent constructs predicting PCTS usage intentions, while there are five constructs shown on the structural model in Appendix 3. The fifth construct resulted from factor analysis of questions B1 to B13 and was labelled 'Optimism'. A review of the remaining four constructs lead to them being renamed. While similar to the constructs in the conceptual model, these factors were subsequently given labels to appropriately reflect the items that loaded on each factor identified in an exploratory factor analysis. The factors were labelled:

- $\quad$ Self Health Evaluation (variables A9 - A12, C1)

- Health Consciousness (variables B3, B8, B9, B11, B12)

- Environmental Action (variables B14 - B19)

- Optimism (variables B2, B4, B6)

- Environmental Consciousness (variables B1, B5, B7, B13)

These 5 constructs were tested as predictors of the dependent variable 'Usage Intentions towards a $\underline{P C T S}$ ' using hierarchical regression analysis. Each factor was entered as a separate block of variables to the regression model.

The model summary is shown in Appendix 2. The significant relationships are shown in the shaded rows.

The analysis of the model shows that $33.4 \%$ of the total variance in Usage Intentions towards a PCTS was predicted by the 5 blocks of variables.

The Self Health Evaluation, Health Consciousness, and Optimism blocks of variables were significant at the $95 \%$ confidence interval with $4.9 \%, 6.5 \%$, and $6.4 \%$ of the total variance in Usage Intentions towards a PCTS explained by each block respectively. The Environmental
Consciousness block of variables was also significant and it explained the highest level of variance of any of the 5 blocks, accounting for $14 \%$ of the total variance in Usage Intentions towards a PCTS. The Environmental Action block of variables was not significant in this model and accounted for only $1.9 \%$ of the total variance.

Examination of the coefficient matrix showed that 5 of the 22 variables were individually significant in explaining the variance in Usage Intentions towards a PCTS. The variances explained by the individual variables that were significant are shown on the model in Appendix 3.

None of the variables in the Environmental Action block were significant, however variable B17 "I look to buy second hand over brand new" was close $(p=0.053)$. This block of variables explained only $1.9 \%$ of the overall variance in Usage Intentions towards a PCTS.

Of the four blocks of variables that were significant, the following individual variables from each were significant at the $95 \%$ confidence interval or greater:

- $\quad$ Self Health Evaluation - C1 "How often do you engage in leisure time physical activity for the sole purpose of improving or maintaining your health" $(p=0.002)$

- Health Consciousness - B9 "I am confident I could maintain a healthy body weight if I wanted to" $(p=0.022)$

- Optimism - B6 "A financial incentive would encourage me to reduce my environmental impact" $(p<0.001)$

- Environmental Consciousness - B1 "I buy environmentally friendly products as much as I can" ( $p=0.002)$ and B13 "I am worried about climate change" $(p<0.001)$

It was expected that Environmental Action would explain a significant level of variance in Usage Intentions Towards a PCTS because it was surmised that individuals who display positive environmental actions could be expected to have positive usage intentions towards a PCTS and vice versa. Therefore, that the relationship between Environmental Action and Usage Intentions towards a PCTS was not significant is of particular note. However given the focus of the broader project is the impact of an understanding of an individual's carbon footprint on their health, then it is expected that a significant relationship between these variables may become evident in the next stage of the project. That it is not significant from 
the analysis of the baseline data may be a stronger indication of misunderstanding surrounding PCTS than being truly reflective of the relationship between these two constructs. Thus the need to include this measure in the next stage of the study and the need for any researchers to consider its inclusion in future studies.

\section{Discussion of the Results}

Five factors were identified from the analysis as the independent variables to be entered to the regression model. The differences between the conceptual model and the regression model were the regression model showed Self Health Evaluation, Health Consciousness, Optimism and Environmental Consciousness were significant predictors of Usage Intentions towards a PCTS however Environmental Action was not. It was thought that Environmental Action would be significant as individuals who have positive environmental actions could reasonably be expected to have positive usage intentions towards PCTS and vice versa, hence its inclusion in the conceptual model. Being found not to be significant has led to it being surmised that the positive environmental actions of the vast majority of Norfolk Islanders may result from financial reasons. Due to the geographic location of Norfolk Island all resources have to be shipped to the island and electricity, fuel and imported food are far more expensive than on the mainland. Because of this extra financial cost, residents are far more likely to have solar electricity and solar hot water systems and engage in positive environmental actions and behaviours regardless of their usage intentions towards PCTS. While some residents do engage in positive environmental actions for environmental reasons, it is thought that others do it out of necessity. The unique characteristics of the Norfolk Island sample and their environment could mean they are atypical and their responses may not necessarily reflect the attitudes of respondents from other locations.

Another possible reason may be the 'valueaction gap' which can occur when an individuals' values and beliefs do not correlate with their actions. This gap is especially prevalent in environmental policy where environmental beliefs do not always translate into behaviours and actions $^{34}$. While this theory was not tested it is interesting to contrast Environmental Action with Environmental Consciousness. The latter variable measures an individual's attitudes and beliefs towards their carbon footprint and climate change as opposed to their behaviours. In the regression model, Environmental Consciousness explained the highest level of variance of all of the constructs.

While Environmental Action was found to be non-significant, it will still be investigated in the next stages of the project to assess users' usage intentions towards a PCTS after having used the PCTS that was developed for this study for 12 months. While it was not significant in the baseline, it is thought that an individual's understanding of their carbon footprint will inform their environmental behaviours as well as their attitudes to the environment and climate change.

NICHE researchers recognize that the survey that is reported on as the basis of this paper was a baseline survey to gather data on individual and household attitudes prior to the roll-out of a PCTS on the Island and that the significant predictors of Usage Intentions Towards a PCTS may change once the users have used the NICHE PCTS and more fully understand how their actions and behaviours affect their carbon footprint. As part of the next stage of the NICHE project an interim survey was conducted in late 2014. The relationships reported in this paper between the constructs and the dependent variable were revisited to see if using a PCTS changes what constructs are significant predictors of usage intentions towards a PCTS. The data analysis from the follow-up survey is currently underway and will be reported at a later date.

\section{Limitations of the study}

The fact that Norfolk Island is a closed system makes it ideal for this study but it also presents some limitations. While the population is reasonably representative of other developed locations its geographic isolation can reasonably be expected to affect attitudes and behaviours towards the environment, climate change and health.

Another limitation of the study is that the survey was administered to gather both household data and individual data. Since only one member of each household was required to fill out the survey it has to be recognized that the attitudes and beliefs reflect that person's views rather than the views held by all members of the household. Attempts were made to try and randomize the sample of residents from each household who filled out the survey. The age distribution of survey 
respondents was similar to the NICHE 2011 census however there were some differences, particularly in the 20 - 29 year age band. A higher percentage of females $(59.8 \%)$ filled out the survey for their household than males $(40.2 \%)$. However, due to the high number of responses $(n=423)$ the survey could be held to be representative of the views of the broader population of Norfolk Island.

The unique nature of the NICHE study also makes it difficult to identify other research of this nature for comparative purposes. The lack of comparative research means that the conceptual model and the scales developed to measure the constructs were tested for the first time in this study. 'Optimism' was identified from the study and is a new construct that was not identified from any related literature. This suggests that there may be other constructs that could affect usage intentions towards PCTS that were not considered by the NICHE researchers.

A further limitation of the research was the anonymity of the NICHE survey. This did not allow researchers to follow up individual respondents or households with further questions. For example, it would have been interesting to follow up with respondents about the factor 'Environmental Action' and its non-significance in the model. This was an unexpected outcome of the research and may be a reflection of the individual survey items or could truly reflect the attitudes of those respondents.

It also needs to be recognized that this was a baseline survey to gather data on individual and household attitudes prior to the roll-out of a PCTS on the Island.

\section{Implications and relevance for future research}

\subsection{Contribution to the Literature}

A number of studies have looked at the political acceptability of PCT in different countries ${ }^{34,35,36,37,38,39,40,41,42}$. While most of this research has primarily focused on the UK in recent years several research projects have focused on political acceptability and the implementation of PCT in Australia ${ }^{43,44}$. There has also been considerable research studying carbon emissions and climate change and the link between them. Much of this research has looked at individuals' beliefs surrounding the causes of climate change. Limited research has also looked at health and obesity and the causes behind and links between them. However an extensive review of the literature was unable to identify research into how all of these factors fit together and influence an individual's usage intention towards PCTS. It is felt that the NICHE project is the first study of its kind to explore how an individual's attitudes and behaviours in these areas influence their usage intention towards a PCTS. This research is highly relevant to any future research in these areas and gives future researchers a solid foundation to further explore the relationship between these attitudes and behaviours and their effect on PCTS. .

\subsection{Practical Implications}

Capping emissions through the use of PCT is one of the main proposals put forward to reduce carbon emissions. The use of PCT has been proposed in many countries and has been implemented in the European Union (EU). There have been a number of studies that have looked at the level of support for PCT however there has been no research into what attitudes and behaviours affect these levels of support. The research reported here into what attitudes and behaviours affect an individual's usage intention towards a PCTS is highly relevant for researchers seeking to understand how PCTS will be accepted by a population as a whole.

As this appears to be the first research of its kind to measure usage intentions towards PCTS it will provide researchers with a validated model as a basis for future research. The scales that were developed to measure the constructs for the conceptual model will also provide a starting point for any future research of this nature

\section{References}

1. Roberts, I. (2007) How the obesity epidemic is aggravating global warming, New Scientist, 2610: 21 .

2. Egger, G., Swinburn, B. (2011) Planet Obesity: How we're eating ourselves and the planet to death, Allen and Unwin.

3. Foresight (2012) Tackling Obesities: Future Choices, URL http://www.foresight.gov.uk/Obesity/Obesity final/Index.htm (accessed January 2012).

4. Costello, A., Abbas, M., Allen, A., Ball, S., Bellamy, R., Friel, S., Grace, N., Johnson, A., Kett, M., Lee, M., Levy, C., Maslin, M.,

Published by Atlantis Press

Copyright: the authors 
McCoy, D., McGuire, B., Montgomery, H., Napier, D., Pagel, C., Patel, J., de Oliveira, J.A.P., Redclift, N., Rees, H., Rogger, D., Scott, J., Stepenson, J., Twigg, J., Wolff, J., Patterson, C. (2009) Managing the health effects of climate change, The Lancet, Vol. 373: 1693-1733.

5. Egger G. (2008) Dousing our inflammatory environment(s): Is personal carbon trading an option for reducing obesity - and climate change?, Obesity Reviews, 9(5): 456-463.

6. Faergeman O. (2007) Climate change and preventive medicine, European Journal of Cardiovascular Prevention and Rehabilitation, 14:726-729.

7. Roberts, S., Thurmin, J. (2006) Centre for Sustainable Energy. A rough guide to individual carbon trading: the issues, ideas and the next steps. Report to DEFRA, November,

URL http://www.defra.gov.uk/environment/climat echange/uk/individual/pca/pdf/pcascopingstudy.pdf (accessed Mar 2007).

8. Fleming D. (2005) Energy and the Common Purpose: Descending the Energy Staircase with Tradable Energy Quotas (TEQs). The Lean Economy Connection: London, URL http://www.theleaneconsomyconnection.net (accessed January 2008).

9. Fawcet T, Bottrill C, Boardman B, Lye G. (2007) Trialing personal carbon allowances, Report for the ZUK Energy Research Centre (UKERC/RR/DR/2007/002), December.

10. House of Commons Environmental Audit Committee (2008) Personal Carbon Trading Fifth Report of 2007-8, London: Stationary Office Ltd., May.

11. Kahn Ribeiro, S., S. Kobayashi, M. Beuthe, J. Gasca, D. Greene, D. S. Lee, Y. Muromachi, P. J. Newton, S. Plotkin, D. Sperling, R. Wit, P. J. Zhou, 2007: Transport and its infrastructure. In Climate Change 2007: Mitigation. Contribution of Working Group III to the Fourth Assessment Report of the Intergovernmental Panel on Climate Change [B. Metz, O.R. Davidson, P.R. Bosch, R. Dave, L.A. Meyer (eds)], Cambridge University Press, Cambridge, United Kingdom and New York, NY, USA.

12. Edwards, P., Roberts, I. (2009) Population adiposity and climate change, International Journal of Epidemiology, 38(4), 1137-1140.

13. Higgins, P. A. (2005) Exercise-based transportation reduces oil dependence, carbon emissions and obesity, Environmental Conservation, 32(3), 197-202.

14. Higgins, P. A., Higgins, M. (2005) A healthy reduction in oil consumption and carbon emissions, Energy Policy, 33(1), 1-4.
15. Woodcock, J., Edwards, P., Tonne, C., Armstrong, B. G., Ashiru, O., Banister, D., Beevers, S., Chalabi, Z., Chowdzury, Z., Cohen A., Franco, O.H., Haines, A., Hickman, R., Lindsay, G., Mittal, I., Mohan, D., Tiwari, G., Woodward, A., Roberts, I. (2009) Public health benefits of strategies to reduce greenhouse-gas emissions: urban land transport, The Lancet, 374(9705), 19301943.

16. Carlsson-Kanyama, A., \& González, A. D. (2009). Potential contributions of food consumption patterns to climate change. The American Journal of Clinical Nutrition, 89(5), 1704S-1709S.

17. Smith, P., Martino, D., Cai, Z., Gwary, D., Janzen, H., Kumar, P., . . . Sirotenko, O. (2007). Agriculture. Climate Change 2007: Mitigation. Contribution of Working Group III to the Fourth Assessment Report of the Intergovernmental Panel on Climate Change.

18. Virtanen, Y., Kurppa, S., Saarinen, M., Katajajuuri, J.-M., Usva, K., Mäenpää, I., . . . Nissinen, A. (2011). Carbon footprint of foodapproaches from national input-output statistics and a LCA of a food portion. Journal of Cleaner Production, 19(16), 1849-1856.

19. Wallén, A., Brandt, N., \& Wennersten, R. (2004). Does the Swedish consumer's choice of food influence greenhouse gas emissions? Environmental Science \& Policy, 7(6), 525535.

20. Egger, G., \& Swinburn, B. (2011). Planet Obesity: How we're eating ourselves and the planet to death: Allen and Unwin.

21. Hawkes, C. (2006). Uneven dietary development: linking the policies and processes of globalization with the nutrition transition, obesity and diet-related chronic diseases. Globalization and health, 2(1), 4.

22. Spencer, E., Appleby, P., Davey, G., \& Key, T. (2003). Diet and body mass index in 38000 EPIC-Oxford meat-eaters, fish-eaters, vegetarians and vegans. International Journal of Obesity, 27(6), 728-734.

23. Stuckler, D., McKee, M., Ebrahim, S., \& Basu, S. (2012). Manufacturing epidemics: the role of global producers in increased consumption of unhealthy commodities including processed foods, alcohol, and tobacco. PLoS Medicine, 9(6), e1001235.

24. Wang, Y., \& Beydoun, M. A. (2009). Meat consumption is associated with obesity and central obesity among US adults. International Journal of Obesity, 33(6), 621-628.

25. Hossain, P., Kawar, B., El Nahas, M. (2007) Obesity and diabetes in the developing world - a growing challenge, New England Journal of Medicine, 356(3), 213-215. 
26. Kushi, L. H., Byers, T., Doyle, C., Bandera, E. V., McCullough, M., Gansler, T., Andrews, K.S., Thun, M. J. (2006) American Cancer Society Guidelines on Nutrition and Physical Activity for cancer prevention: reducing the risk of cancer with healthy food choices and physical activity, CA: a cancer journal for clinicians, 56(5), 254-281.

27. Leviston, Z., \& Walker, I. (2011). Baseline Survey of Australian attitudes to climate change: PRELIMINARY REPORT: CSIRO.

28. Leviston, Z., Leitch, A., Greenhill, M., Leonard, R., \& Walker, I. (2011). Australians' views of climate change. Canberra: CSIRO Report. Retrieved January, 15, 2013.

29. Department of Environment Climate Change and Water NSW. (2010). Who cares about the environment in 2009?

30. World Health Organization. (2008). The WHO STEPwise approach to chronic disease risk factor surveillance (STEPS). Armstrong, T., \& Bull, F. (2006). Development of the World Health Organization Global Physical Activity Questionnaire (GPAQ).

31. Capstick, S., \& Lewis, A. (2009). Personal carbon allowances: a pilot simulation and questionnaire. UK Energy Research Centre, London.

32. Taylor, B., \& McNiel, P. (2011). Norfolk Island 2011 Census of Population and Housing.

33. Blake, J. (1999). Overcoming the 'value-action gap'in environmental policy: Tensions between national policy and local experience. Local environment, 4(3), 257-278.

34. Bird, J., Jones, N., Lockwood, M. (2008) Political acceptability of personal carbon trading: Findings from primary research, London, IPPR.

35. Bristow, A. L., Wardman, M., Zanni, A. M., Chintakayala, P. K. (2010) Public acceptability of personal carbon trading and carbon tax, Ecological Economics, 69(9), 1824-1837.
36. Capstick, S., \& Lewis, A. (2009) Personal carbon allowances: a pilot simulation and questionnaire, UK Energy Research Centre, London.

37. Energy Saving Trust. (2007) Green barometer: Measuring environmental attitudes, Energy Saving Trust, London.

38. Jagers, S. C., Löfgren, Å., Stripple, J. (2009) Attitudes to Personal Carbon Allowances: The effect of trust in politicians, perceived fairness and ideology, Working Papers in Economics 360 ,

http://www.gu.se/english/research/publication/ ?publicationId=93377 - accessed 03/10/2014.

39. Keay-Bright, S., Fawcett, T., Howell, R., Parag, Y. (2008) Personal Carbon Trading (PCT): Bringing together the research community, Paper presented at the Workshop Report.

40. Owen, L., Edgar, L., Prince, S., Doble, C. (2008). Personal carbon trading: public acceptability: a report to the Department for Environment, Food and Rural Affairs, Opinion Leader \& Enviros Consulting, London.

41. Parag, Y., Eyre, N. (2010) Barriers to personal carbon trading in the policy arena. Climate Policy, 10(4), 353-368.

42. Wallace, A. A. (2009) Reducing carbon emissions by households: the effects of footprinting and personal allowances, Institute of Energy and Sustainable Development, De Montfort University, Leicester.

43. Akter, S., Bennett, J. (2011) Household perceptions of climate change and preferences for mitigation action: the case of the Carbon Pollution Reduction Scheme in Australia, Climatic Change, 109(3-4), 417-436.

44. Leviston, Z., Leitch, A., Greenhill, M., Leonard, R., Walker, I. (2011). Australians' views of climate change, Canberra: CSIRO Report. Retrieved January, 15, 2013. 
Hendry et al.

\section{Appendix 1 - NICHE Conceptual Model}

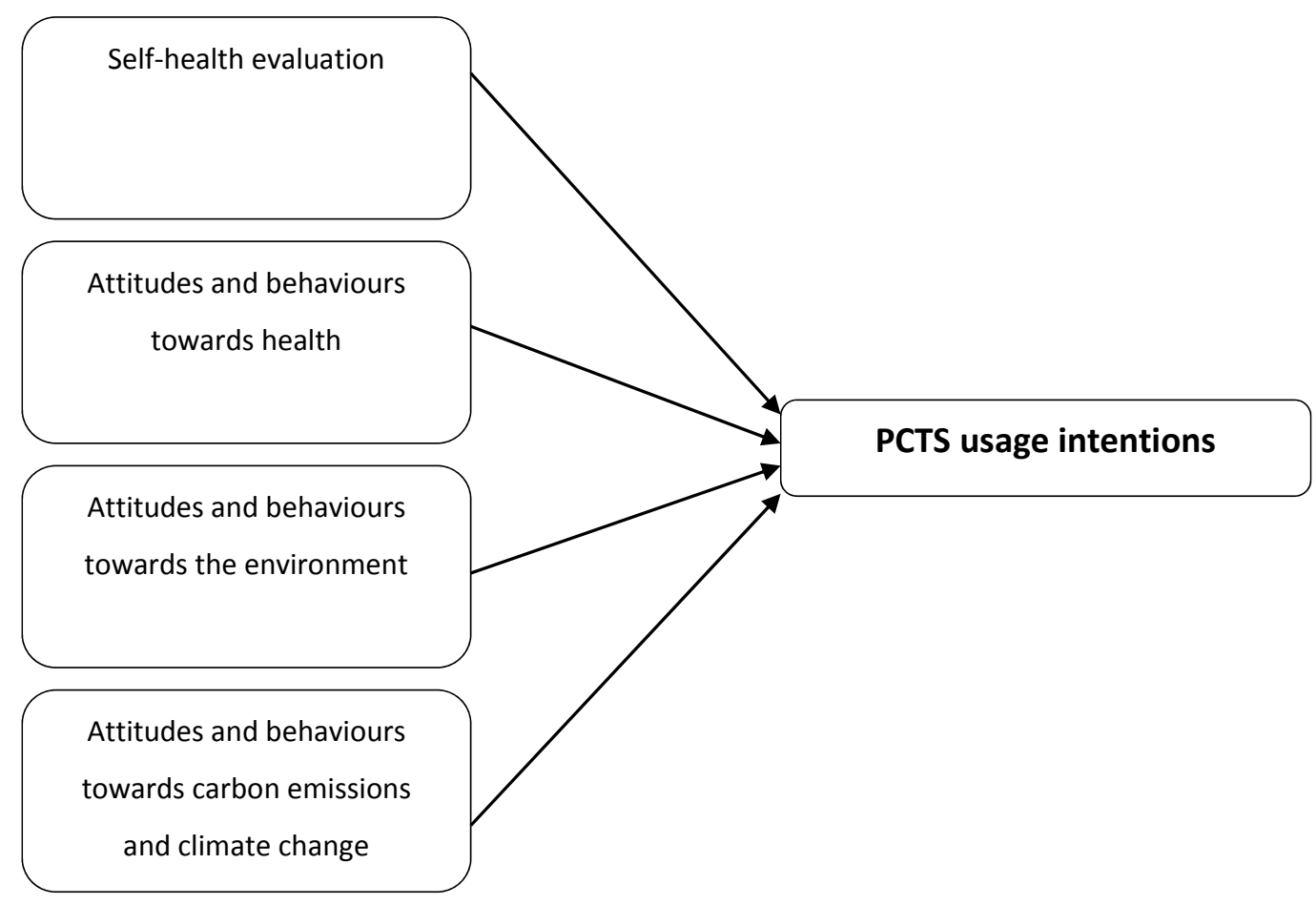




\section{Appendix 3 - Variances in Usage Intentions towards a PCTS}

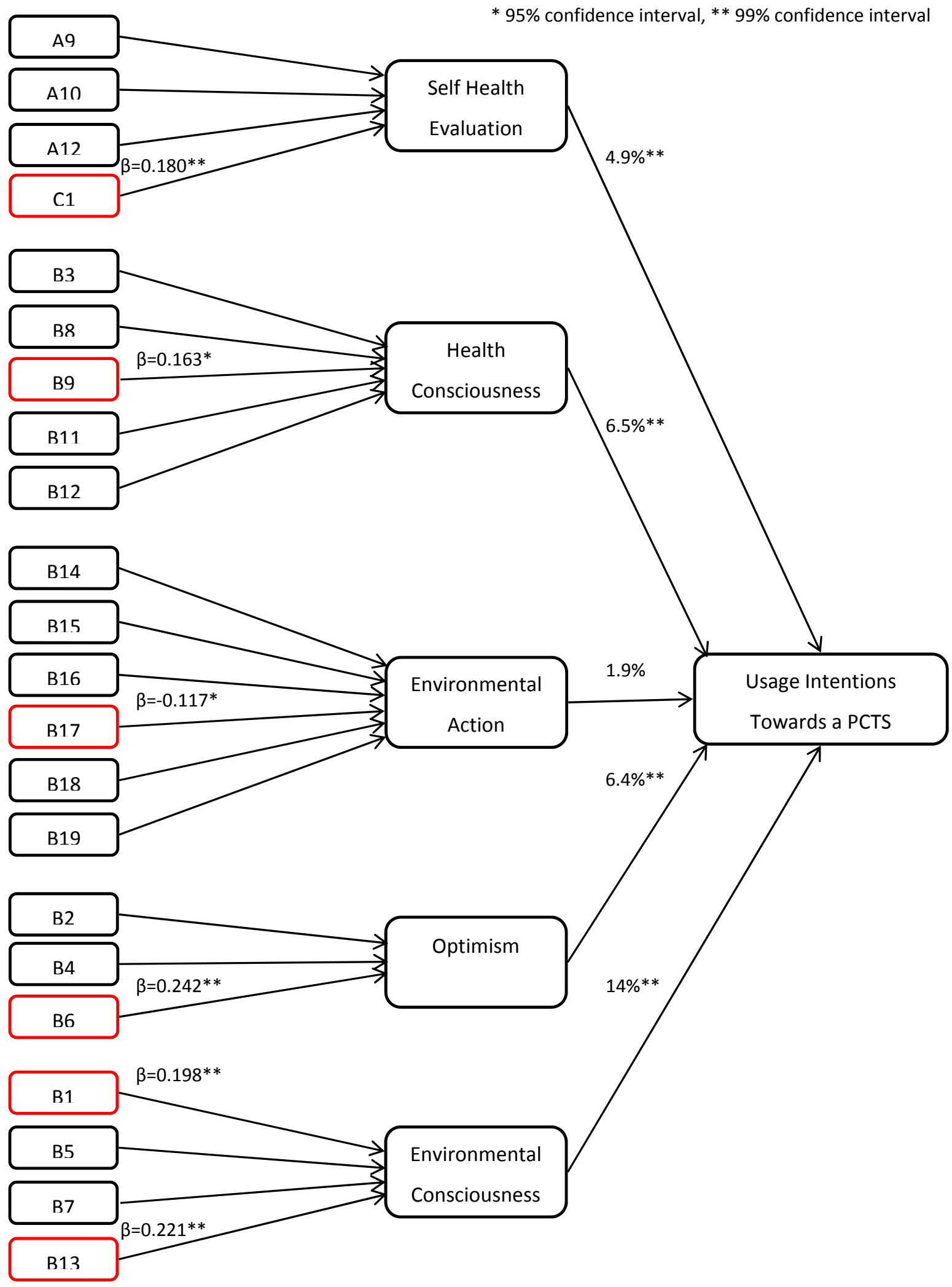

Published by Atlantis Press

Copyright: the authors 